\title{
DNA damage responses in mammalian oocytes
}

\author{
Josie K Collins and Keith T Jones \\ Centre for Biological Sciences, Faculty of Natural and Environmental Sciences, University of Southampton, \\ Southampton, UK
}

Correspondence should be addressed to K T Jones, Email: k.t.jones@soton.ac.uk; J K Collins, Email: jkc1g10@soton.ac.uk

\begin{abstract}
DNA damage acquired during meiosis can lead to infertility and miscarriage. Hence, it should be important for an oocyte to be able to detect and respond to such events in order to make a healthy egg. Here, the strategies taken by oocytes during their stages of growth to respond to DNA damaging events are reviewed. In particular, recent evidence of a novel pathway in fully grown oocytes helps prevent the formation of mature eggs with DNA damage. It has been found that fully grown germinal vesicle stage oocytes that have been DNA damaged do not arrest at this point in meiosis, but instead undergo meiotic resumption and stall during the first meiotic division. The Spindle Assembly Checkpoint, which is a well-known mitotic pathway employed by somatic cells to monitor chromosome attachment to spindle microtubules, appears to be utilised by oocytes also to respond to DNA damage. As such maturing oocytes are arrested at metaphase I due to an active Spindle Assembly Checkpoint. This is surprising given this checkpoint has been previously studied in oocytes and considered to be weak and ineffectual because of its poor ability to be activated in response to microtubule attachment errors. Therefore, the involvement of the Spindle Assembly Checkpoint in DNA damage responses of mature oocytes during meiosis I uncovers a novel second function for this ubiquitous cellular checkpoint.

Reproduction (2016) 152 R15-R22
\end{abstract}

\section{Introduction}

An effective response to DNA damage is crucial for all cells including oocytes (Sancar et al. 2004). Extensive damage occurring throughout meiosis can have severe consequences if an appropriate response is not taken and can result in infertility or defective embryo development (Kirk \& Lyon 1982, Meirow et al. 2001, Adriaens et al. 2009). Mammalian oocytes remain arrested at the dictyate stage of meiosis for an extended period, up to several decades in some species including humans (Mehlmann 2005, Chiang et al. 2012, Holt et al. 2013, Jones et al. 2013). Such a lengthy arrest provides an opportunity for the accumulation of DNA damage.

Insults to DNA can also result from exogenous factors throughout a woman's reproductive life, particularly during the treatment for cancer (Roness et al. 2014). With a large number of effective anti-neoplastic treatments now available, survival rate among cancer patients has increased (Aziz \& Rowland 2003, Dillman \& McClure 2014). Therefore, an emerging problem is the long-term effects of such life-saving treatments, including the loss of fertility in both sexes. In women, cancer therapy often results in premature ovarian failure (POF) because the lifetime supply of oocytes in the ovary is killed off by aggressive cancer treatment (Maltaris et al. 2007). The most effective and established method used to preserve fertility in some women is the cryopreservation of embryos and oocytes (Maltaris et al. 2007, ASRM 2013, Roness et al. 2014, Skaznik-Wikiel et al. 2015). Unfortunately, these methods cannot be applied to all. One limitation of this technique is that a partner, or willingness to use a donor, is required to provide sperm. Hormonal suppression of ovaries during cancer treatment is another option for women; however, the use of such drugs has potential associated risks such as interference with the cancer treatment or survival of eggs with DNA damage (Roness et al. 2014).

However, the major limitation of cryopreservation methods is that they can only be used in post-pubertal women. Therefore, there are currently no established options for young pre-pubertal girls (Skaznik-Wikiel et al. 2015). Experimental options include ovarian tissue cryopreservation, but this has a variety of risks associated with it (Maltaris et al. 2007, Skaznik-Wikiel et al. 2015).

In this review, we will focus on the various strategies that oocytes elicit, in the adult, upon damage to their DNA. This includes the apoptosis of primordial follicles, evasion of the G2/M checkpoint and a metaphase arrest induced by DNA damage. Programmed doublestrand breaks (DSBs) occur in foetal life during meiotic recombination and pose a potential threat to oocytes if left unrepaired. However, only responses to exogenous sources of DNA damage will be discussed here. 


\section{Primordial follicle apoptosis after DNA damage}

At birth, the reserve of oocytes has been established and is held within primordial follicles arrested at prophase of meiosis I (Pepling 2006, Pepling \& Spradling 2001). These follicles are important as they will provide the oocytes for future post-pubertal ovulations throughout reproductive life, and therefore, the effect of DNA damage on primordial follicles is of much significance for fertility. There are several types of DNA damage, including crosslinks and base alterations, which are reviewed elsewhere (Sancar et al. 2004); however, one of the more dangerous types of damage is DSBs. This is due to the fact that a variety of chromosomal aberrations can be induced, including chromosomal translocations and rearrangements, if DNA DSB repair is aberrant (Richardson \& Jasin 2000, Ferguson \& Alt 2001, larovaia et al. 2014). A cell can respond in many ways to DNA damage, including but not limited to, inducing an arrest in the cell cycle, or initiation of apoptosis if the damage is severe (Roos \& Kaina 2006, 2013, Sancar et al. 2004). Indeed, it is well documented that primordial follicle stage oocytes with damaged DNA readily undergo apoptosis (Suh et al. 2006, Livera et al. 2008, Kerr et al. 2012a, Roness et al. 2014) (Fig. 1). Likewise, somatic cells will undergo apoptosis if a G1/S arrest is sustained

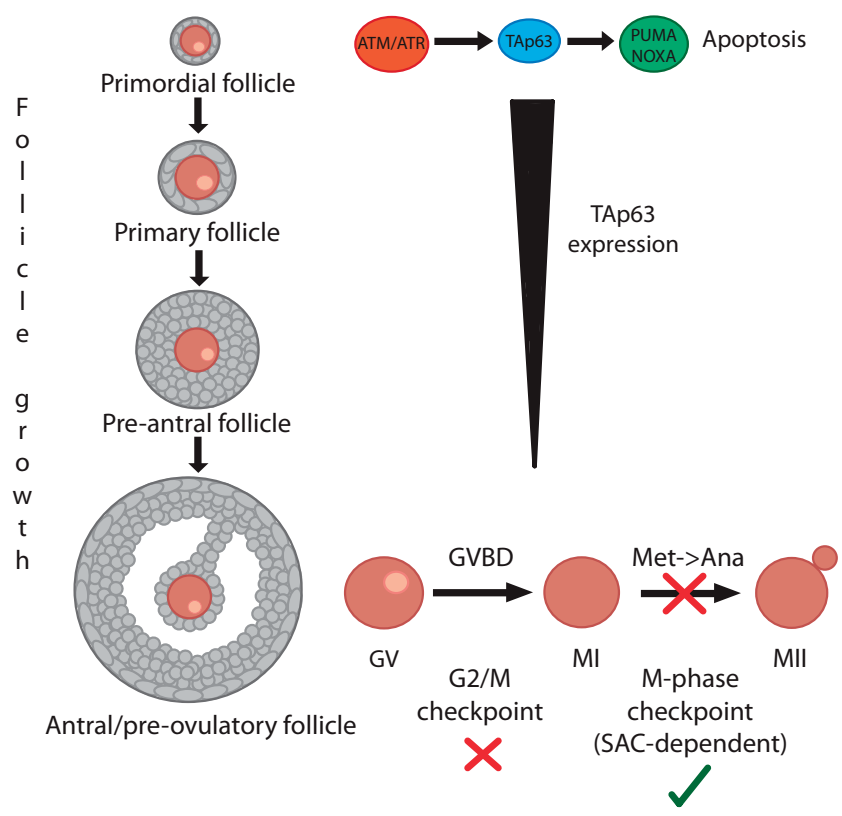

Figure 1 Oocyte responses to DNA damage. Primordial and primary follicles express TAp63, allowing them to respond to DNA damage by inducing apoptosis. However, TAp63 expression diminishes by the late antral stage. Fully grown oocytes from antral follicles cannot induce a robust G2/M checkpoint (i.e. at the GV stage), in contrast to somatic cells, but instead resume meiosis with DNA damage. Instead, oocytes have a checkpoint response that allows damaged oocytes to arrest at metaphase I, and which is dependent on SAC. and contain extensive DNA damage that cannot be repaired (Nowsheen \& Yang 2012, Roos \& Kaina 2013).

p53, a transcription factor, is necessary for the maintenance of the $\mathrm{G} 1 / \mathrm{S}$ checkpoint in a somatic cell with DNA damage (Basu \& Haldar 1998). The initiation of this checkpoint requires activation of the master kinases ataxia telangiectasia mutated (ATM) and ataxia telangiectasia and $\mathrm{Rad}-3$ related (ATR) (Smith et al. 2010). In response to DSBs, these kinases are known to phosphorylate histone 2AX (H2AX) at serine 139 (Bakkenist \& Kastan 2003, Burma et al. 2001). Such post-translational modification at the site of damage provides a platform for other DNA damage response (DDR) proteins to assemble on DNA in the event of damage. ATM/ATR kinases also phosphorylate, and activate, several other DDR signalling proteins (Shiloh \& Ziv 2013). p53 phosphorylation by ATM and ATR kinases at serine 15 (Loughery et al. 2014) and by $\mathrm{CHK} 1 / \mathrm{CHK} 2$ kinases at serine 20 aids its activation (Chehab et al. 1999). Modifications to MDM2, the p53 ubiquitin ligase binding partner, have also been reported to allow the two to dissociate and to stabilise p53 (Cheng et al. 2009). Post-translational modifications of p53 retain it within the nucleus, allowing it to upregulate p21, a cyclin-dependent kinase (CDK) inhibitor, as well as directly blocking the transcription of cell cycle regulators (Fig. 2A).

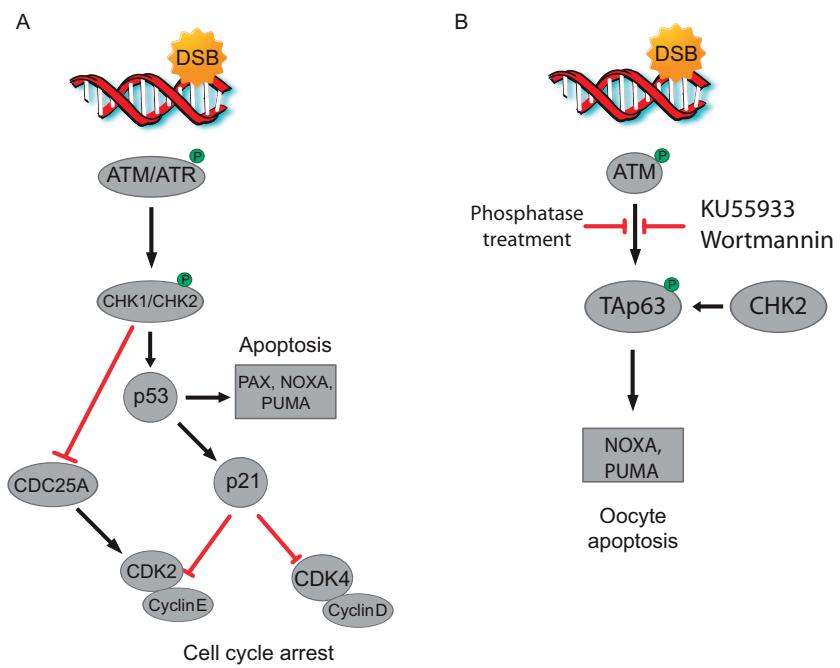

Figure 2 The G1/S checkpoint in somatic cells and the oocyte equivalent. (A) G1/S checkpoint: DNA damage in the form of DSBs primarily leads to the activation of the master kinases ATM/ATR. These kinases can lead to the phosphorylation of CHK1/CHK2. Both CHK1/CHK2 and ATM/ATR activate the p53 transcription factor. p53 is essential for increasing the transcription of p21, an inhibitor of CDK complexes needed for entry into S-phase. When DNA damage is severe and cannot be repaired, p53-dependent transcription of genes such as Noxa and Puma causes apoptotic pathways to be activated. (B) DNA damage response in oocytes from primordial follicles: ATM is activated upon damage and phosphorylates TAp63. Also CHK2 has been shown to be involved in TAp63 activation. TAp63 induces apoptosis by inducing the transcription of Noxa and Puma. 
Loss of p53 in mice leads to greater susceptibility to spontaneous and induced tumours, giving it the moniker 'guardian of the genome' (Donehower et al. 1992). Interestingly, results obtained from $\mathrm{p} 53^{-/-}$ oocytes suggested that it is not an essential component for DNA damage-induced apoptosis in the female germ line (Suh et al. 2006), and instead the role is fulfilled by other members of the p53 family such as p63 and p73 (Levrero et al. 2000). Indeed, in oocytes, one important 'guardian' appears to be trans-activating p63 (TAp63) (Suh et al. 2006, Livera et al. 2008, Kerr et al. 2012b) (Fig. 2B). Experiments using PCR and studies on knockout mice revealed that the prevalent form of TAp63 in oocytes is TAp63 $\alpha$ (Livera et al. 2008). The expression profile of TAp63 has also been mapped throughout oogenesis and oocyte maturation in mice. Embryonic expression is very limited; however, by postnatal day 5, all oocytes express the transcription factor (Suh et al. 2006, Kim \& Suh 2014). The lack of TAp63 expression allows embryonic oocytes to evade apoptosis, whereas oocytes retrieved from the ovaries of 5-day-old mice die within a few days of irradiation (Kim \& Suh 2014). To highlight the importance of TAp63 in the DNA damageinduced apoptosis, TAp63-/- mice were irradiated and ovaries were harvested several days later. In such mice, primordial follicles did not undergo apoptosis after exposure to gamma-irradiation, strongly implying that TAp63 is essential for the induction of apoptosis (Suh et al. 2006).

To activate TAp63 after DNA damage induction, ATM kinase and CHK2 are required (Suh et al. 2006, Livera et al. 2008, Bolcun-Filas et al. 2014). The requirement for phosphorylation in the activation of TAp63 has been shown using phosphatase treatment, as this prevented its mobility shift seen on immunoblots following ionising radiation (Suh et al. 2006, Livera et al. 2008). This shift is only seen in mice from postnatal day 5 onwards and so is absent in newborn oocytes (Kim \& Suh 2014), implying that before this the kinases responsible are under inhibitory regulation. The involvement of ATM kinase specifically in activating TAp63 was recently shown by Kim and Suh (2014), where treatment with pharmacological inhibitors, KU55933 or Wortmannin, blocked apoptosis. CHK2 has also been found to be involved in the activation of TAp63 (Bolcun-Filas et al. 2014). In Chk2-/- ovaries, TAp63 remained un-phosphorylated after ionising radiation exposure, and its absence allowed oocytes to survive despite the presence of DNA damage (Bolcun-Filas et al. 2014).

As well as the upstream components that lead to apoptosis, the downstream signalling of the p53 family is of considerable interest. In somatic cells, p53 initiates apoptosis by increasing the expression pro-apoptotic factors such as NOXA (PMAIP1), PUMA (BBC3) and BAX (Basu \& Haldar 1998, Roos \& Kaina 2006, 2013). These proteins are members of the BCL2 family and act as pro-apoptotic factors by leading to activation of caspase-9, a crucial caspase during intrinsic apoptosis (Elmore 2007). As one may expect, TAp63 is the essential transcription factor for the expression of NOXA and PUMA in oocytes from 5-day-old mice (Kerr et al. 2012b). Puma ${ }^{-1-}$, Noxa $^{-/-}$and Puma ${ }^{-/-}$Noxa $^{-/-}$ ovaries maintain many primordial follicles after ionising radiation treatment compared with wild-type controls, which rapidly deplete. This suggests that the expression of PUMA and NOXA is what drives primordial follicle apoptosis after DNA damage. Not only are these follicles protected from loss, but the knockout also preserved fertility, indicated by the production of multiple litters without gross abnormalities. The lack of abnormality suggests that these irradiated oocytes, which do not undergo apoptosis, have the ability to repair DNA damage over time (Kerr et al. 2012b). As well as the preservation of fertility, Noxa- and Puma-knockout mice have no increased susceptibility to cancer. For the future, if NOXA and PUMA could be targeted when women undergo cancer treatment, it could potentially be used as a way to reduce the prevalence of POF in these women without an increased cancer risk caused by the treatment itself.

\section{GV oocytes possess a weak G2/M checkpoint}

TAp63 expression is dramatically lost when a follicle is recruited for ovulation (Suh et al. 2006). Therefore, it was unknown what effect DNA damage has on oocytes from larger antral follicles, once fully grown and meiotically competent. Although primordial follicles constitute the vast majority of the population of oocytes in the ovary, it is interesting to determine how fully grown oocytes behave in response to DNA damage as these are temporally closer to creating an embryo.

When an oocyte is growing, it remains arrested in prophase of meiosis I (Mehlmann 2005). As well as this, several factors within an oocyte need to reach a threshold level such as Cdk1, in order for the oocyte to become competent to complete meiosis (deVantery et al. 1996). The biochemical mechanism of prophase arrest and meiotic resumption has been extensively reviewed elsewhere and so will not be discussed further here (Mehlmann 2005, Holt et al. 2013, Jones et al. 2013) (Fig. 3A). However, it is worth noting that there are several similarities in the transition from GV arrest to meiotic resumption and the G2/M transition of a somatic cell (Solc et al. 2010). Most notable here is that both processes are triggered by CDK1 (Adhikari et al. 2012, Adhikari \& Liu 2014). Due to this similarity, it was assumed that the oocyte would have the ability to initiate a GV arrest when exposed to genotoxic agents because somatic cells arrest at G2 in response to DNA damage. However, the first studies that looked into the effect of DNA DSBs in fully grown GV oocytes in mice revealed that in contrast to mitotic cells, oocytes do 
A

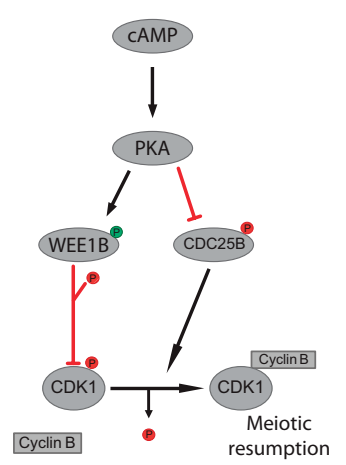

B

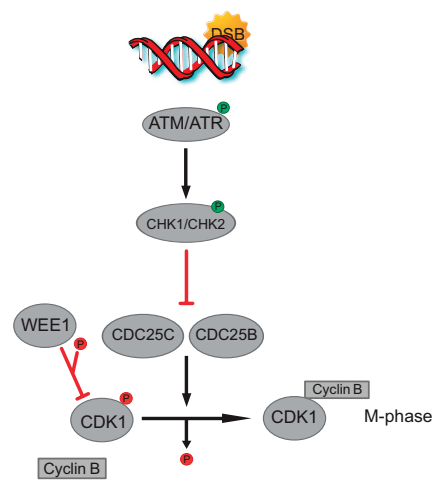

Figure 3 The somatic G2/M checkpoint and GV arrest in oocytes. (A) Maintenance of GV arrest in oocytes: cyclic AMP is required for the activation of PKA. This kinase is responsible for the regulation of two key proteins: WEE1B and CDC25B. Maintaining GV arrest requires $C D C 25 B$ to be inactive, preventing the removal of inhibitory phosphates from CDK1. The inhibitory modifications to CDK1 are carried out by WEE1B. Without an active CDK1-cyclin B1 complex, meiotic resumption cannot take place. (B) G2/M checkpoint in somatic cells: as with the G1/S checkpoint, DSBs initiate the activation of several kinases including ATM/ATR and CHK1/CHK2. In the $\mathrm{G} 2 / \mathrm{M}$ checkpoint, $\mathrm{CHK} 1 / \mathrm{CHK} 2$ is responsible for inhibiting the action of CDC25 phosphatases. CDC25 is the normal cause of M-phase entry, removing inhibitory phosphates from CDK1, and so allowing cyclin B to bind, a process obligatory for CDK1 activity to rise.

not induce a robust G2/M checkpoint after exposure to the drug etoposide (Marangos et al. 2015, Marangos \& Carroll 2012) (Fig. 1). Etoposide induces DSBs by inhibiting the release of topoisomerase II from DNA (Nitiss 2009). This creates a protein-DNA complex that has to be cleaved, which forms a DSB capped by remnants of the topoisomerase enzyme. It is only very high concentrations of either etoposide or doxorubicin that delay meiotic entry. Similar findings have since been observed by other groups, again using etoposide (Collins et al. 2015), and other DNA damaging agents such as neocarzinostatin (NCS) (Yuen et al. 2012, Mayer et al. 2016), bleomycin, ionising radiation and UV-B exposure (Collins et al. 2015). Ionising radiation induces a majority of its DSBs through the generation of reactive oxygen species (ROS) (Desouky et al. 2015). Chemical agents such as Bleomycin and NCS also induce DSBs in DNA by acting as ionising radiation mimetics (Chen \& Stubbe 2004). UV damage can induce several forms of DNA damage including pyrimidine dimers, oxidative damage to bases and also DSBs primarily through the formation of ROS but also as a secondary effect of dimer repair (Sinha \& Hader 2002, Rastogi et al. 2010). There is likely to be a lack of a G2 checkpoint in all mammalian species, not just mice, because porcine oocytes do not appear to initiate a checkpoint either (Wang et al. 2015). Recently, it has been suggested that the presence of cumulus cells may allow for oocytes to remain GV arrested when their DNA is damaged (Sun et al. 2015).

This could potentially provide some protection against the formation of a fully mature egg with DNA damage in vivo.

Nevertheless, the absence of an efficient DNA damage checkpoint in prophase-arrested oocytes is considered to be due to a lack of ATM kinase activation (Marangos \& Carroll 2012). This contrasts to a somatic cell in which the response to DNA damage at the G2/M checkpoint switches on in this kinase (Bakkenist \& Kastan 2003) (Fig. 3B). Only very high levels of DNA damage in oocytes were able to activate ATM (Marangos \& Carroll 2012, Wang et al. 2015). In mouse oocytes, this culminates in a CHK1-dependent inhibitory phosphorylation of CDC25B, and so maintenance of GV arrest (Marangos \& Carroll 2012). The lack of ATM activation in oocytes, compared with somatic cells, is considered to be due to low levels of ATM expression, and possibly the specific chromatin configuration in fully grown oocytes, leading to a failure of the DDR pathway to be fully implemented (Marangos \& Carroll 2012).

\section{An oocyte-specific DNA damage checkpoint}

Once it was established that oocytes do not induce a robust checkpoint if exposed to genotoxins when GV arrested, it was of interest whether or not an alternative mechanism exists at some point later in meiosis to prevent the formation of a fertilisable egg. Having undergone GV breakdown, the oocyte then needs to progress through meiosis I, and arrest at metaphase of meiosis II, where it remains until fertilisation (Jones \& Lane 2013). However, fully grown GV oocytes exposed to genotoxic agents such as NCS (Yuen et al. 2012), etoposide (Collins et al. 2015, Marangos et al. 2015), UV-B and ionising radiation (Collins et al. 2015) do not reach metaphase II and instead arrest in meiosis I (Fig. 1). Interestingly, treatment with mitomycin C (Yuen et al. 2012), to induce interstrand crosslinks, or treatment with very low doses (ng/mL) of NCS (Mayer et al. 2016), does not appear to prevent polar body extrusion. The lack of response to interstrand crosslinks could allow this type of damage to be present in the mature oocyte. If left unrepaired, such genetic insults could lead to severe perturbations during embryonic development if fertilised.

The block in meiosis I seen after most forms of DNA damage occurs before the metaphase to anaphase transition (Collins et al. 2015, Marangos et al. 2015). This transition is one of the major events in oocyte maturation, with bivalents reductionally segregating into sister chromatids. The bivalent structure is maintained by cohesin. To allow the physical separation of bivalents, the cleavage of cohesin is required, which is achieved by the protease separase (Terret et al. 2003). Separase is kept inactive until anaphase onset by CDK1dependent phosphorylation and a chaperone-binding protein securin (Terret et al. 2003). Therefore, in order to achieve anaphase, securin loss is essential, as well as 
a decrease in CDK1 activity, which is caused by the loss of cyclin B1 (Herbert et al. 2003). Both cyclin B1 and securin loss is brought about by ubiquitylation from the anaphase promoting complex/cyclosome (APC) (Homer 2013). DNA damage in oocytes appears to prevent APC activation (Collins et al. 2015).

A well-characterised M-phase arrest brought about by APC inhibition is observed in somatic cells at a time when chromosomes are not fully attached to microtubules and under tension from the mitotic spindle. The surveillance system that keeps the APC inactive is the Spindle Assembly Checkpoint (SAC) and prevents mis-segregation of chromosomes by coupling anaphase with correct chromosome alignment (Khodjakov \& Pines 2010). Many of its components were first discovered in yeast, but have since been identified in mammalian model systems and oocytes including MAD1, MAD2, BUBR1 and MPS1. However, the female meiotic SAC is considered to be less effective at preventing missegregation events (Kitajima et al. 2011, Gui \& Homer 2012, Kolano et al. 2012, Lane et al. 2012, Nagaoka et al. 2011, Sebestova et al. 2012), and such ineffectiveness has been associated with the higher rates of bivalent missegregation in oocytes leading to aneuploidy (Nagaoka et al. 2011, Jones \& Lane 2013).

Despite the previous labelling of the oocyte SAC as being weak or ineffectual in responding to microtubule attachment errors, it does appear to be, by contrast, remarkably effective at preventing anaphase after treatment with genotoxic agents (Fig. 4). Several SAC components including MAD2, BUBR1 and MPS1 have all been shown to be heavily involved in this arrest (Collins et al. 2015, Marangos et al. 2015). Activation of the SAC after DNA damage does not appear to occur at the sites of DNA damage, instead evidence suggests that DNA damage is sensed at the kinetochore, where these proteins usually accumulate during canonical SAC signalling (Collins et al. 2015, Marangos et al. 2015). DNA damage caused by DSBs would have the potential to fragment DNA. As such bivalent fragments could contain only a single pair of sister kinetochores that may have the capacity only to mono-orientate, and so activate the SAC due to lack of tension development. However, such bivalent fragments do not appear to be the cause of arrest as they are not present consistently or in sufficient number in DNA damage-arrested oocytes (Collins et al. 2015). Also oocytes with biorientation errors induced by the spindle poison, nocodazole, still undergo anaphase without delay (Collins et al. 2015) (Fig. 4).

The presence of such a checkpoint raises questions about the signalling cascade that takes place in oocytes upstream of SAC activation. Of particular interest is whether a link between the DNA damage checkpoint and the SAC exists in oocytes. There are already links uncovered between the two cellular checkpoints in somatic cells. For instance, BUBR1 and BUB1 have been shown to be required for the
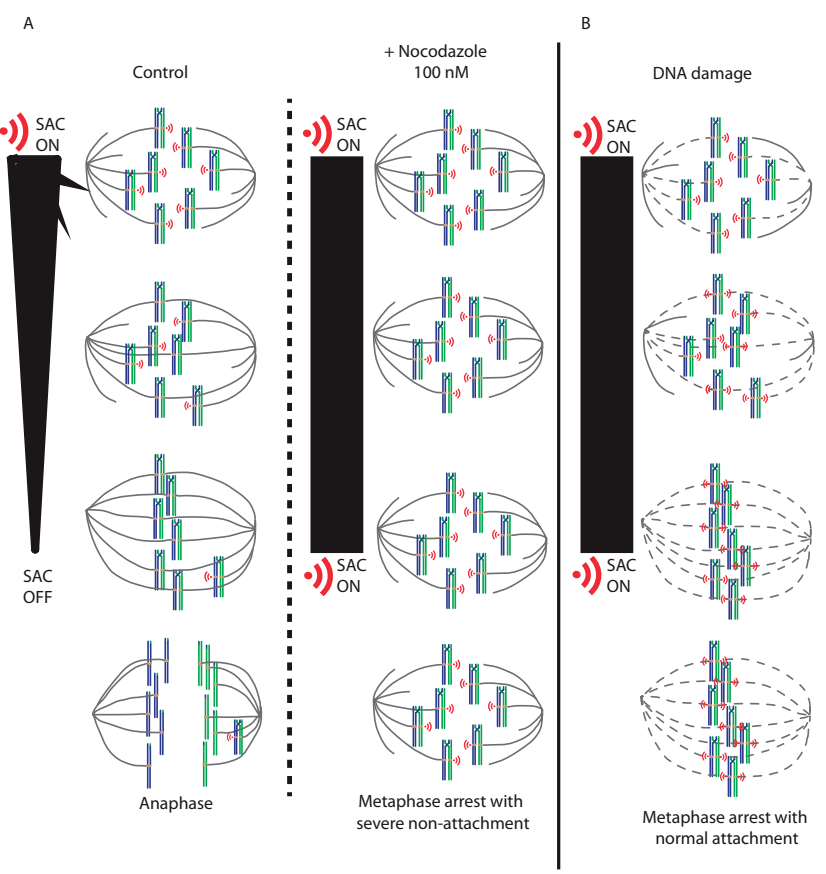

Figure 4 Relative sensitivity of the SAC to biorientation and DNA damage in oocytes. (A) Oocyte SAC response to non-attachment: during early prometaphase, there are several bivalents without correct microtubule attachment to the spindle. These unattached kinetochores provide a sufficient signal for SAC activity to prevent anaphase. However, the SAC signal (for currently unknown reasons) appears not as effective as in somatic cells in responding to attachment, and alignment, errors. As such oocytes can undergo anaphase with non-aligned bivalents. Only upon treatment with nocodazole, to induce high levels of bivalent non-attachment, is anaphase prevented. (B) Oocyte SAC in response to DNA damage: the SAC appears very efficient at causing a metaphase arrest when DNA has been damaged, and yet the spindle appears unaffected, with aligned bivalents at the metaphase plate. The nature of the attachment of these bivalents to the microtubules (grey dashed line) is currently unknown. The SAC signalling in response to DNA damage is considered to initiate at the kinetochore rather than at the sites of DNA damage.

DNA damage response in Drosophila embryos and HeLa cells respectively (Royou et al. 2005, Yang et al. 2012). Also, the DDR protein CHK1 appears to be involved in SAC function in avian (Zachos et al. 2007) and mammalian cell lines (Peddibhotla et al. 2009). Several SAC components, including MPS1 and MAD2, have been shown to be crucial for the DNA damage-induced metaphase arrest in oocytes (Collins et al. 2015, Marangos et al. 2015). Also, the MOS/ MAP kinase (MAPK) pathway, known to have a role in activating the meiotic SAC (Nabti et al. 2014), appears to be integral for activating the DNA damage checkpoint in oocytes (Marangos et al. 2015).

Although ATM is involved in DNA damage-induced apoptosis in primordial follicles (Kim \& Suh 2014), it appears not to contribute to SAC activation after DNA damage induction in fully grown GV oocytes, as pharmacological inhibition of the kinase does not rescue 
polar body extrusion in damaged oocytes (Marangos et al. 2015). This may not be too surprising given the reported lack of ATM activation in GV stage oocytes following DNA damage (Marangos \& Carroll 2012). This contrasts with somatic cells where ATM has been implicated in SAC activation after nocodazole treatment (Eliezer et al. 2014). Another DDR protein, MDC1, has also been suggested to be able to directly interact with the APC, an interaction that is heightened after DNA damage (Coster et al. 2007).

An alternative candidate for activating the oocyte DNA damage checkpoint would be ATR. This kinase is known to be involved in $\mathrm{H} 2 \mathrm{AX}$ phosphorylation after UV exposure in somatic cells (Hanasoge \& Ljungman 2007) and is activated by single-stranded DNA generated during the repair of DNA damage (Zou \& Elledge 2003). It also functions in establishing a G2/M checkpoint in mammalian cell lines independent of ATM kinase activity (Xue et al. 2015). Another DDR protein that could be involved in DNA damage-induced SAC activation is CHK1. Manipulating the levels of this protein has highlighted its involvement in maintaining prophase arrest and in potentially activating the SAC (Chen et al. 2012).

Regardless of the mechanism activating the checkpoint, it is clear that for most DNA damaging agents tested, a robust arrest in meiosis I is initiated and maintained (Collins et al. 2015). Future work is likely to focus on the upstream signalling before SAC activation and whether any other traditional DDR proteins are involved in the oocyte checkpoint.

\section{Conclusions}

The oocyte studies presented here have begun to uncover the strategies employed to prevent the formation of a mature egg with DNA damage. Although it is clear that TAp63-induced apoptosis is responsible for the loss of damaged oocytes from primordial follicles, this pathway is lost once a follicle is recruited for ovulation. Furthermore, fully grown oocytes from mature follicles ready for ovulation do not undergo apoptosis and have a very poor ' $\mathrm{G} 2 / \mathrm{M}$ ' checkpoint when DSBs are induced. Instead oocytes with DNA damage are arrested in meiosis I through the actions of the SAC, which can now be viewed as a major checkpoint in preventing the creation of embryos with DNA damage. Future studies need to address the full set of players in this pathway, particularly the involvement of traditional DNA damage response proteins described in somatic cells.

\section{Declaration of interest}

The authors declare that there is no conflict of interest that could be perceived as prejudicing the impartiality of the research reported.

\section{Funding}

This work was funded by a BBSRC grant to $\mathrm{KJ}$ (mechanisms of DNA damage and repair in mature oocytes, BBSRC, BB/ L006006/1).

\section{References}

Adhikari D \& Liu K 2014 The regulation of maturation promoting factor during prophase I arrest and meiotic entry in mammalian oocytes. Molecular and Cellular Endocrinology 382 480-487. (doi:10.1016/j. mce.2013.07.027)

Adhikari D, Zheng W, Shen Y, Gorre N, Ning Y, Halet G, Kaldis P \& Liu K 2012 Cdk1, but not Cdk2, is the sole Cdk that is essential and sufficient to drive resumption of meiosis in mouse oocytes. Human Molecular Genetics 21 2476-2484. (doi:10.1093/hmg/dds061)

Adriaens I, Smitz J \& Jacquet P 2009 The current knowledge on radiosensitivity of ovarian follicle development stages. Human Reproduction Update 15 359-377. (doi:10.1093/humupd/dmn063)

ASRM 2013 Mature oocyte cryopreservation: a guideline. Fertility and Sterility 99 37-43. (doi:10.1016/j.fertnstert.2012.09.028)

Aziz NM \& Rowland JH 2003 Trends and advances in cancer survivorship research: challenge and opportunity 1. Seminars in Radiation Oncology 13 248-266. (doi:10.1016/S1053-4296(03)00024-9)

Bakkenist CJ \& Kastan MB 2003 DNA damage activates ATM through intermolecular autophosphorylation and dimer dissociation. Nature $\mathbf{4 2 1}$ 499-506. (doi:10.1038/nature01368)

Basu A \& Haldar S 1998 The relationship between Bcl2, Bax and p53: consequences for cell cycle progression and cell death. Molecular Human Reproduction 4 1099-1109. (doi:10.1093/molehr/4.12.1099)

Bolcun-Filas E, Rinaldi VD, White ME \& Schimenti JC 2014 Reversal of female infertility by Chk2 ablation reveals the oocyte DNA damage checkpoint pathway. Science 343 533-536. (doi:10.1126/science.1247671)

Burma S, Chen BP, Murphy M, Kurimasa A \& Chen DJ 2001 ATM phosphorylates histone $\mathrm{H} 2 \mathrm{AX}$ in response to DNA double-strand breaks. Journal of Biological Chemistry 276 42462-42467. (doi:10.1074/jbc. C100466200)

Chehab N, Malikzay A, Stavridi E \& Halazonetis TD 1999 Phosphorylation of Ser-20 mediates stabilization of human p53 in response to DNA damage. PNAS 96 13777-13782. (doi:10.1073/pnas.96.24.13777)

Chen JY \& Stubbe JA 2004 Bleomycins: new methods will allow reinvestigation of old issues. Current Opinion in Chemical Biology $\mathbf{8}$ 175-181. (doi:10.1016/j.cbpa.2004.02.008)

Chen L, Chao S-B, Wang Z-B, Qi S-T, Zhu X-L, Yang S-W, Yang C-R, Zhang Q-H, Ouyang Y-C, Hou Y et al. 2012 Checkpoint kinase 1 is essential for meiotic cell cycle regulation in mouse oocytes. Cell Cycle 11 1948-1955. (doi:10.4161/cc.20279)

Cheng Q, Chen L, Li Z, Lane WS \& Chen J 2009 ATM activates p53 by regulating MDM2 oligomerization and E3 processivity. EMBO Journal 28 3857-3867. (doi:10.1038/emboj.2009.294)

Chiang T, Schultz RM \& Lampson MA 2012 Meiotic origins of maternal age-related aneuploidy. Biology of Reproduction 86 7. (doi:10.1095/ biolreprod.111.094367)

Collins JK, Lane SIR, Merriman JA \& Jones KT 2015 DNA damage induces a meiotic arrest in mouse oocytes mediated by the spindle assembly checkpoint. Nature Communications 6 8553. (doi:10.1038/ncomms9553)

Coster G, Hayouka Z, Argaman L, Strauss C, Friedler A, Brandeis M \& Goldberg M 2007 The DNA damage response mediator MDC1 directly interacts with the anaphase-promoting complex/cyclosome. Journal of Biological Chemistry 282 32053-32064. (doi:10.1074/jbc.M705890200)

Desouky O, Ding N \& Zhou G 2015 Targeted and non-targeted effects of ionizing radiation. Journal of Radiation Research and Applied Sciences $\mathbf{8}$ 247-254. (doi:10.1016/j.jrras.2015.03.003)

deVantery C, Gavin AC, Vassalli JD \& SchorderetSlatkine S 1996 An accumulation of $\mathrm{p} 34(\mathrm{cdc} 2)$ at the end of mouse oocyte growth correlates with the acquisition of meiotic competence. Developmental Biology 174 335-344. (doi:10.1006/dbio.1996.0078)

Dillman RO \& McClure SE 2014 Steadily improving survival in lung cancer. Clinical Lung Cancer 15 331-337. (doi:10.1016/j.cllc.2014.05.006)

Donehower LA, Harvey M, Slagle BL, McArthur MJ, Montgomery CA, Butel JS \& Bradley A 1992 Mice deficient for p53 are developmentally 
normal but susceptible to spontaneous tumours. Nature 356 215-221. (doi:10.1038/356215a0)

Eliezer Y, Argaman L, Kornowski M, Roniger M \& Goldberg M 2014 Interplay between the DNA damage proteins MDC1 and ATM in the regulation of the spindle assembly checkpoint. Journal of Biological Chemistry 289 8182-8193. (doi:10.1074/jbc.M113.532739)

Elmore S 2007 Apoptosis: a review of programmed cell death. Toxicologic Pathology 35 495-516. (doi:10.1080/01926230701320337)

Ferguson DO \& Alt FW 2001 DNA double strand break repair and chromosomal translocation: lessons from animal models. Oncogene $\mathbf{2 0}$ 5572-5579.

Gui L \& Homer H 2012 Spindle assembly checkpoint signalling is uncoupled from chromosomal position in mouse oocytes. Development 139 1941-1946. (doi:10.1242/dev.078352)

Hanasoge S \& Ljungman M 2007 H2AX phosphorylation after UV irradiation is triggered by DNA repair intermediates and is mediated by the ATR kinase. Carcinogenesis 28 2298-2304. (doi:10.1093/carcin/ bgm157)

Herbert M, Levasser M, Homer H, Yallop K, Murdoch A \& McDougall A 2003 Homologue disjunction in mouse oocytes requires proteolysis of securin and cyclin B1. Nature Cell Biology 5 1023-1025. (doi:10.1038/ ncb1062)

Holt JE, Lane SIR \& Jones KT 2013 Chapter seven - the control of meiotic maturation in mammalian oocytes. In Current Topics in Developmental Biology, pp 207-226. Ed MW Paul. San Diego, CA, USA: Academic Press. (doi:10.1016/B978-0-12-416024-8.00007-6)

Homer H 2013 The APC/C in female mammalian meiosis I. Reproduction 146 R61-R71. (doi:10.1530/REP-13-0163)

larovaia OV, Rubtsov M, loudinkova E, Tsfasman T, Razin SV \& Vassetzky YS 2014 Dynamics of double strand breaks and chromosomal translocations. Molecular Cancer 13 249. (doi:10.1186/1476-4598-13-249)

Jones KT \& Lane SI 2013 Molecular causes of aneuploidy in mammalian eggs. Development 140 3719-3730. (doi:10.1242/dev.090589)

Jones K, Lane SR \& Holt J 2013 Start and stop signals of oocyte meiotic maturation. In Oogenesis, pp 183-193. Eds G Coticchio, DF Albertini \& L De Santis. London, UK: Springer. (doi:10.1007/978-0-85729-826-3_13)

Kerr JB, Brogan L, Myers M, Hut KJ, Mladenovska T, Ricardo S, Hamza K, Scott CL, Strasser A \& Findlay JK 2012a The primordial follicle reserve is not renewed after chemical or gamma-irradiation mediated depletion. Reproduction 143 469-476. (doi:10.1530/REP-11-0430)

Kerr JB, Hutt KJ, Michalak EM, Cook M, Vandenberg CJ, Liew SH, Bouillet P, Mills A, Scott CL, Findlay JK \& Strasser A 2012b DNA damage-induced primordial follicle oocyte apoptosis and loss of fertility require TAp63-mediated induction of puma and noxa. Molecular Cell 48 343-352. (doi:10.1016/j.molcel.2012.08.017)

Khodjakov A \& Pines J 2010 Centromere tension: a divisive issue. Nature Cell Biology 12 919-923. (doi:10.1038/ncb1010-919)

Kim D-A \& Suh E-K 2014 Defying DNA double-strand break-induced death during prophase I meiosis by temporal TAp63 alpha phosphorylation regulation in developing mouse oocytes. Molecular and Cellular Biology 34 1460-1473. (doi:10.1128/MCB.01223-13)

Kirk M \& Lyon MF 1982 Induction of congenital anomalies in offspring of female mice exposed to varying doses of X-rays. Mutation Research/ Fundamental and Molecular Mechanisms of Mutagenesis 106 73-83. (doi:10.1016/0027-5107(82)90191-9)

Kitajima TS, Ohsugi M \& Ellenberg J 2011 Complete kinetochore tracking reveals error-prone homologous chromosome biorientation in mammalian oocytes. Cell 146 568-581. (doi:10.1016/j.cell.2011.07.031)

Kolano A, Brunet S, Silk AD, Cleveland DW \& Verlhac MH 2012 Errorprone mammalian female meiosis from silencing the spindle assembly checkpoint without normal interkinetochore tension. PNAS 109 E1858E1867. (doi:10.1073/pnas.1204686109)

Lane SI, Yun Y \& Jones KT 2012 Timing of anaphase-promoting complex activation in mouse oocytes is predicted by microtubule-kinetochore attachment but not by bivalent alignment or tension. Development 139 1947-1955. (doi:10.1242/dev.077040)

Levrero M, De Laurenzi V, Costanzo A, Sabatini S, Gong J, Wang JYJ \& Melino G 2000 The p53/p63/p73 family of transcription factors: overlapping and distinct functions. Journal of Cell Science 1131661 1670.

Livera G, Petre-Lazar B, Guerquin M-J, Trautmann E, Coffigny H \& Habert R 2008 p63 null mutation protects mouse oocytes from radioinduced apoptosis. Reproduction 135 3-12. (doi:10.1530/REP-07-0054)
Loughery J, Cox M, Smith LM \& Meek DW 2014 Critical role for p53-serine 15 phosphorylation in stimulating transactivation at p53-responsive promoters. Nucleic Acids Research 42 7664-7680. (doi:10.1093/nar/ gku501)

Maltaris T, Seufert R, Fischl F, Schaffrath M, Pollow K, Koelbl H \& Dittrich R 2007 The effect of cancer treatment on female fertility and strategies for preserving fertility. European Journal of Obstetrics Gynecology and Reproductive Biology 130 148-155. (doi:10.1016/j.ejogrb.2006.08.006)

Marangos P \& Carroll J 2012 Oocytes progress beyond prophase in the presence of DNA damage. Current Biology 22 989-994. (doi:10.1016/j. cub.2012.03.063)

Marangos P, Stevense M, Niaka K, Lagoudaki M, Nabti I, Jessberger R \& Carroll J 2015 DNA damage-induced metaphase I arrest is mediated by the spindle assembly checkpoint and maternal age. Nature Communications 6 8706. (doi:10.1038/ncomms9706)

Mayer A, Baran V, Sakakibara Y, Brzakova A, Ferencova I, Motlik J, Kitajima TS, Schultz RM \& Solc P 2016 DNA damage response during mouse oocyte maturation. Cell Cycle 15 546-558. (doi:10.1080/15384 101.2015.1128592)

Mehlmann LM 2005 Stops and starts in mammalian oocytes: recent advances in understanding the regulation of meiotic arrest and oocyte maturation. Reproduction 130 791-799. (doi:10.1530/rep.1.00793)

Meirow D, Epstein M, Lewis H, Nugent D \& Gosden RG 2001 Administration of cyclophosphamide at different stages of follicular maturation in mice: effects on reproductive performance and fetal malformations. Human Reproduction 16 632-637. (doi:10.1093/humrep/16.4.632)

Nabti I, Marangos P, Bormann J, Kudo NR \& Carroll J 2014 Dualmode regulation of the $\mathrm{APC} / \mathrm{C}$ by $\mathrm{CDK} 1$ and MAPK controls meiosis I progression and fidelity. Journal of Cell Biology 204 891-900. (doi:10.1083/jcb.201305049)

Nagaoka SI, Hodges CA, Albertini DF \& Hunt PA 2011 Oocyte-specific differences in cell-cycle control create an innate susceptibility to meiotic errors. Current Biology 21 651-657. (doi:10.1016/j.cub.2011.03.003)

Nitiss JL 2009 Targeting DNA topoisomerase II in cancer chemotherapy. Nature Reviews Cancer 9 338-350. (doi:10.1038/nrc2607)

Nowsheen S \& Yang ES 2012 The intersection between DNA damage response and cell death pathways. Experimental Oncology 34 243-254.

Peddibhotla S, Lam MH, Gonzalez-Rimbau M \& Rosen JM 2009 The DNA-damage effector checkpoint kinase 1 is essential for chromosome segregation and cytokinesis. PNAS 106 5159-5164. (doi:10.1073/ pnas.0806671106)

Pepling ME 2006 From primordial germ cell to primordial follicle: mammalian female germ cell development. Genesis 44 622-632. (doi:10.1002/(ISSN)1526-968X)

Pepling ME \& Spradling AC 2001 Mouse ovarian germ cell cysts undergo programmed breakdown to form primordial follicles. Developmental Biology 234 339-351. (doi:10.1006/dbio.2001.0269)

Rastogi RP, Richa KA, Tyagi MB \& Sinha RP 2010 Molecular mechanisms of ultraviolet radiation-induced DNA damage and repair. Journal of Nucleic Acids 2010 592980. (doi:10.4061/2010/592980)

Richardson C \& Jasin M 2000 Frequent chromosomal translocations induced by DNA double-strand breaks. Nature 405 697-700. (doi:10.1038/35015097)

Roness H, Kalich-Philosoph L \& Meirow D 2014 Prevention of chemotherapy-induced ovarian damage: possible roles for hormonal and non-hormonal attenuating agents. Human Reproduction Update 20 759-774. (doi:10.1093/humupd/dmu019)

Roos WP \& Kaina B 2006 DNA damage-induced cell death by apoptosis. Trends in Molecular Medicine 12 440-450. (doi:10.1016/j. molmed.2006.07.007)

Roos WP \& Kaina B 2013 DNA damage-induced cell death: From specific DNA lesions to the DNA damage response and apoptosis. Cancer Letters 332 237-248. (doi:10.1016/j.canlet.2012.01.007)

Royou A, Macias H \& Sullivan W 2005 The Drosophila Grp/Chk1 DNA damage checkpoint controls entry into anaphase. Current Biology 15 334-339. (doi:10.1016/j.cub.2005.02.026)

Sancar A, Lindsey-Boltz LA, Unsal-Kacmaz K \& Linn S 2004 Molecular mechanisms of mammalian DNA repair and the DNA damage checkpoints. Annual Review of Biochemistry 73 39-85. (doi:10.1146/ annurev.biochem.73.011303.073723)

Sebestova J, Danylevska A, Novakova L, Kubelka M \& Anger M 2012 Lack of response to unaligned chromosomes in mammalian female gametes. Cell Cycle 11 3011-3018. (doi:10.4161/cc.21398) 
Shiloh Y \& Ziv Y 2013 The ATM protein kinase: regulating the cellular response to genotoxic stress, and more. Nature Reviews. Molecular Cell Biology 14 197-210. (doi:10.1038/nrm3546)

Sinha RP \& Hader DP 2002 UV-induced DNA damage and repair: a review. Photochemical \& Photobiological Sciences 1 225-236. (doi:10.1039/B201230H)

Skaznik-Wikiel ME, Gilbert SB, Meacham RB \& Kondapalli LA 2015 Fertility preservation options for men and women with cancer. Reviews in Urology 17 211-219.

Smith J, Tho LM, Xu N \& Gillespie DA 2010 The ATM-Chk2 and ATR-Chk1 pathways in DNA damage signaling and cancer. Advances in Cancer Research 108 73-112. (doi:10.1016/B978-0-12-380888-2.00003-0)

Solc P, Schultz RM \& Motlik J 2010 Prophase I arrest and progression to metaphase I in mouse oocytes: comparison of resumption of meiosis and recovery from G2-arrest in somatic cells. Molecular Human Reproduction 16 654-664. (doi:10.1093/molehr/gaq034)

Suh E-K, Yang A, Kettenbach A, Bamberger C, Michaelis AH, Zhu Z, Elvin JA, Bronson RT, Crum CP \& McKeon F 2006 p63 protects the female germ line during meiotic arrest. Nature 444 624-628. (doi:10.1038/nature05337)

Sun MH, Zheng J, Xie FY, Shen W, Yin S \& Ma JY 2015 Cumulus cells block oocyte meiotic resumption via gap junctions in cumulus oocyte complexes subjected to DNA double-strand breaks. PLOS ONE 10 e0143223. (doi:10.1371/journal.pone.0143223)

Terret ME, Wassmann K, Waizenegger I, Maro B, Peters JM \& Verlhac MH 2003 The meiosis I-to-meiosis II transition in mouse oocytes requires separase activity. Current Biology 13 1797-1802. (doi:10.1016/j. cub.2003.09.032)

Wang H, Luo Y, Zhao MH, Lin Z, Kwon J, Cui XS \& Kim NH 2015 DNA double-strand breaks disrupted the spindle assembly in porcine oocytes.
Molecular Reproduction and Development 83 132-143. (doi:10.1002/ mrd.22602)

Xue L, Furusawa Y, Okayasu R, Miura M, Cui X, Liu C, Hirayama R, Matsumoto Y, Yajima H \& Yu D 2015 The complexity of DNA double strand break is a crucial factor for activating ATR signaling pathway for G2/M checkpoint regulation regardless of ATM function. DNA Repair 25 72-83. (doi:10.1016/j.dnarep.2014.11.004)

Yang C, Wang $\mathrm{H}$, Xu Y, Brinkman KL, Ishiyama $H$, Wong STC \& Xu B 2012 The kinetochore protein Bub1 participates in the DNA damage response. DNA Repair 11 185-191. (doi:10.1016/j. dnarep.2011.10.018)

Yuen WS, Merriman JA, O'Bryan MK \& Jones KT 2012 DNA double strand breaks but not interstrand crosslinks prevent progress through meiosis in fully grown mouse oocytes. PLOS ONE 7 e43875. (doi:10.1371/journal. pone.0043875)

Zachos G, Black EJ, Walker M, Scott MT, Vagnarelli P, Earnshaw WC \& Gillespie DAF 2007 Chk1 is required for spindle checkpoint function. Developmental Cell 12 247-260. (doi:10.1016/j.devcel.2007.01.003)

Zou L \& Elledge SJ 2003 Sensing DNA damage through ATRIP recognition of RPA-ssDNA complexes. Science $\mathbf{3 0 0}$ 1542-1548. (doi:10.1126/ science.1083430)

Received 15 February 2016

First decision 3 March 2016

Revised manuscript received 23 March 2016

Accepted 7 April 2016 